\title{
PERAN MEDIASI KEPUASAN KERJA PADA PENGARUH WORK- FAMILY CONFLICT TERHADAP TURNOVER INTENTION KARYAWAN HOTEL DAFAM SAVVOYA
}

\author{
I Gede Adi Juliawan ${ }^{1}$ \\ I Gusti Bagus Honor Satrya ${ }^{2}$ \\ ${ }^{1,2}$ Fakultas Ekonomi dan Bisnis Universitas Udayana (Unud), Bali, Indonesia \\ email: adijuliawan17@gmail.com
}

\begin{abstract}
ABSTRAK
Penelitian ini dilakukan pada karyawan Hotel Dafam Savvoya Seminyak, Badung, Bali, Indoneisa. Tujuan penelitian ini adalah untuk mengetahui peran kepuasan kerja memediasi work-family conflict terhadap turnover intention pada Hotel Dafam Savvoya Seminyak, Badung, Bali, Indonesia. Hotel Dafam Savvoya Seminyak, Badung, Bali, Indonesia merupakan salah satu bisnis yang bergerak di bidang akomodasi. Sampel yang diambil sebanyak 33 respoonden. Pengambilan sampel dalam penelitian ini menggunakan teknik purposive sampling. Pengumpulan data dilakukan dengan penyebaran kuesioner dengan menggunakan skala likert 5 poin untuk mengukur 14 item pernyataan. Teknik analisis yang digunakan adalah statistik deskriptif, analisis jalur, uji sobel dan uji asumsi klasik. Hasil analisis menunjukan bahwa work-family conflict berpengaruh positif dan signifikan terhadap turnover intention. Work-family conflict berpengaruh negatif dan signifikan terhadap kepuasan kerja. Kepuasan kerja berpengaruh negatif dan signifikan terhadap turnover intention. Kepuasan kerja memediasi pengaruh work-family conflict terhadap turnover intention. Upaya menurunkan turnover intention pada karyawan, manager atau departemen HRD diharapkan lebih memperhatikan tingkat work-family conflict dan tingkat kepuasan kerja yang dirasakan oleh karyawan. Hal ini bertujuan agar karyawan tidak memiliki pemikiran terkait keinginan turnover intention terhadap perusahaannya.
\end{abstract}

Kata Kunci: turnover intention, work-family conflict, kepuasan kerja

\begin{abstract}
This research was conducted on employees of Dafam Savvoya Hotel Seminyak, Badung, Bali, Indonesia. The purpose of this study was to determine the role of job satisfaction mediating work-family conflict on turnover intention in Savafya Dafam Hotel Seminyak, Badung, Bali, Indonesia. Dafam Savvoya Hotel Seminyak, Badung, Bali, Indonesia is one of the businesses engaged in accommodation. Samples taken were 33 respondents. Sampling in this study using purposive sampling technique. Data collection was carried out by distributing questionnaires using a 5-point Likert scale to measure 14 statement items. The analysis technique used is descriptive statistics, path analysis, simple test and classic assumption test. The analysis shows that work-family conflict has a positive and significant effect on turnover intention. Work-family conflict has a negative and significant effect on job satisfaction. Job satisfaction has a negative and significant effect on turnover intention. Job satisfaction mediates the effect of work-family conflict on turnover intention. Efforts to reduce turnover intention in employees, managers or HRD departments are expected to pay more attention to the level of work-family conflict and the level of job satisfaction felt by employees. It is intended that employees do not have thoughts related to the desire turnover intention towards the company.
\end{abstract}

Keywords: turnover intention, work-family conflict, job satisfaction 


\section{PENDAHULUAN}

Pariwisata merupakan salah satu sektor andalan utama bagi Indonesia. Ini terbukti pariwisata telah memberikan kontribusi yang sangat besar sebagai penyumbang devisa negara. Bali memiliki beragam potensi budaya dan alam yang dapat dijadikan sebagai modal untuk mengembangkan kepariwisataannya (Prayogi, 2011). Bali merupakan salah satu daerah tujuan wisata yang ada di Indonesia. Berbagai keunikan, budaya yang kental dan keindahan alam yang dimiliki menjadi daya tarik bagi para wisatawan mancanegara maupun lokal untuk berkunjung ke Bali. Bisnis yang berkembang pesat dan memberikan kontribusi besar adalah bisnis yang bergerak di bidang akomodasi. Hotel merupakan salah satu industri yang bergerak dalam bidang akomodasi (Kusuma dan Mujiati, 2017).

Bisnis yang berkembang pesat dan memberikan kontribusi besar adalah bisnis yang bergerak di bidang akomodasi. Hotel merupakan salah satu industri yang bergerak dalam bidang akomodasi (Kusuma dan Mujiati, 2017). Kemajuan suatu perusahaan sangat bergantung pada sumber daya manusia (SDM) yang andal khususnya pada industri jasa perhotelan, hotel merupakan perusahaan jasa yang mengedepankan kualitas SDM demi tercapainya tujuan perusahaan (Ksama dan Wibawa, 2016). Prameswari dan Suwanda (2017) bahwa dalam meningkatkan efektifitas dan keberhasilan organisasi sangat tergantung dari sumber daya manusia yang berkualitas. Oleh sebab itu, suatu organisasi harus dapat mengelola sumber daya manusia yang dimiliki agar dapat mendukung tercapainya tujuan suatu organisasi.

Keberhasilan atau tidaknya suatu organisasi atau institusi akan ditentukan oleh faktor manusianya atau karyawannya dalam mencapai tujuannya (Anwar, 2018). Peristiwa yang sering terjadi di dalam suatu sistem dan pengelolaan sumber daya manusia di beberapa perusahaan adalah bagaimana karyawan itu sendiri berperilaku. Salah satu bentuk perilaku dari karyawan tersebut adalah turnover intention yang mengacu dan berujung pada keputusan karyawan untuk meninggalkan pekerjaannya (Ariansyah, 2019). Turnover yang tinggi dapat berdampak buruk bagi organisasi seperti menciptakan ketidakstabilan dan ketidakpastian terhadap kondisi tenaga kerja yang ada serta tingginya biaya pengelolaan SDM seperti biaya pelatihan yang sudah dilakukan pada karyawan sampai dengan biaya rekrutmen dan pelatihan kembali (Sartika, 2014). Kepuasan kerja secara langsung memiliki pengaruh signifikan dan negatif terhadap keinginan karyawan untuk keluar dari tempat kerjanya (Tziner et al., 2015).

Penelitian ini di lakukan di Hotel Dafam Savvoya Seminyak, Badung, Bali, Indonesi. Hotel Dafam Savvoya Seminyak, Badung, Bali, Indonesia merupakan salah satu akomodasi yang bergerak di bidang perhotelan. Hotel Dafam Savvoya Seminyak, Badung, Bali, Indonesia berdiri sejak tahun 2015, yang berlokasi di Jalan Mertanadi No. 14, Seminyak, Badung, Bali, Indonesia. Jumlah karyawan yang berkerja di Hotel Dafam Savvoya Seminyak, Badung, Bali, Indonesia memiliki 50 karyawan. Hotel Dafam Savvoya Seminyak, Badung, Bali, Indonesia telah beroperasi dari bulan September 2015. Selama 5 tahun beroperasi Hotel Dafam Savvoya Seminyak, Badung, Bali, Indonesia megalami beberapa masalah 
salah satunya yaitu adalah turnover tinggi. Tabel 1. menunjukkan turnover dari Hotel Dafam Savvoya Seminyak, Badung, Bali, Indonesia.

Tabel 1.

Turnover karyawan Hotel Dafam Savvoya Seminyak Tahun 2015 - 2019

\begin{tabular}{cccccc}
\hline Tahun & $\begin{array}{c}\text { Jumlah } \\
\text { Karyawan } \\
\text { Awal } \\
\text { Tahun } \\
\text { (orang) }\end{array}$ & $\begin{array}{c}\text { Jumlah } \\
\text { Karyawan } \\
\text { Akhir } \\
\text { Tahun } \\
\text { (orang) }\end{array}$ & $\begin{array}{c}\text { Jumlah } \\
\text { Karyawan } \\
\text { Masuk } \\
\text { (orang) } \\
(\mathbf{( 3 )}\end{array}$ & $\begin{array}{c}\text { Jumlah } \\
\text { Karyawan } \\
\text { Keluar } \\
\text { (orang) } \\
(\mathbf{4})\end{array}$ & $\begin{array}{c}\text { Turnover } \\
\text { Karyawan } \\
(\mathbf{\%})\end{array}$ \\
$\begin{array}{c}\mathbf{( 5 )}= \\
(4)\end{array}$ \\
\hline 2015 & 72 & 66 & 3 & 9 & $13,04 \%$ \\
2016 & 66 & 61 & 5 & 10 & $15,74 \%$ \\
2017 & 61 & 55 & 5 & 11 & $18,96 \%$ \\
2018 & 55 & 50 & 4 & 9 & $17,14 \%$ \\
2019 & 50 & 50 & 8 & 8 & $16,00 \%$ \\
\hline
\end{tabular}

Pada awal periode jumlah keseluruhan karyawan Hotel Dafam Savvoya Seminyak, Badung, Bali, Indonesia adalah 72 karyawan dan pada akhir periode jumlah karyawan sebanyak 50 orang, berdasarkan dari data turnover intention karyawan yang sangat tinggi dan menurut Human Resources Departement (HRD) Hotel Ddafam Savvoya, Seminyak, Badung, Bali, Indonesia terjadi akibat dari karyawan yang melihat peluang lebih bagus bekerja di tempat lain dibandingkan di Hotel Dafam Savvoya, Seminyak, Badung, Bali, Indonesia. Karyawan yang melakukan turnover kebanyakan hanya mencari pengalaman, kemudian lebih memilih untuk bekerja di kapal pesiar.

Persentase turnover karyawan di Hotel Dafam Savvoya, Seminyak, Badung, Bali, Indonesia cenderung meningkat akibat dari jumlah karyawan yang keluar lebih banyak daripada karyawan masuk. Hal yang menyebabkan Hotel Dafam Savvoya, Seminyak, Badung, Bali, Indonesia mengalami penurunan jumlah karyawan setiap tahun akibat dari pergantian manajemen yang menyebabkan berubahnya kebijakan pada periode tersebut yang menyebabkan penyusutan karyawan Hotel Dafam Savvoya, Seminyak, Badung, Bali, Indonesia. Walupun dengan jumlah karyawan 50 orang namun tidak mengurangi efektifitas Hotel Dafam Savvoya Seminyak, Badung, Bali, Indonesia dikarenakan pihak manajemen dan departemen HRD mampu mengefisiensikan tugas dan tanggung jawab kepada karyawan tanpa mengurangi efektifitas dan produktifitas yang maksimal untuk Hotel Dafam Savvoya Seminyak, Badung, Bali, Indonesia.

Dapat diuraikan bahwa dalam Tabel 1 terdapat lebih dari 10 persen terjadinya turnover karyawan dari tahun 2015 sampai dengan tahun 2019. Apabila persentase turnover di suatu perusahaan melebihi 10 persen, dapat diartikan bahwa turnover intention atau keinginan karyawan untuk keluar dari perusahaan yang bersangkutan dapat dikatakan tinggi (Fahrizal dan Utama, 2017). Tripathi dan Pandey (2017) menjelaskan bahwa turnover intention berpengaruh sacara positif terhadap turnover, semakin tingginya keinginan karyawan untuk pindah, maka semakin besar pula tingkat turnover karyawan yang akan terjadi. 
Berdasarkan pra-riset melalui metode wawancara dengan 5 karyawan Hotel Dafam Savvofa Seminyak, Badung, Bali, Indonesia yang terdiri dari satu karyawan departemen Human Resources Departement, satu karyawan departemen Accounting, dua karyawan departemen Housekeeping dan satu karyawan departemen Food \& Beverage. Tingginya tingkat turnover disebabkan oleh beberapa faktor, salah satunya yaitu kurangnya kesempatan bagi karyawan untuk promosi jabatan serta hubungan karyawan dengan karyawan lain diperusahaan, hal ini yang juga menyebabkan karyawan tidak merasa puas karena ada tuntutan yang berat atas pekerjaannya yang membuat karyawan harus bekerja diluar jam kerja yang sudah ditetapkan untuk menyelesaikan pekerjaan mereka. Tekanan waktu juga dialami oleh karyawan yang bekerja melebihi kapasitas tanggung jawab karyawan sehingga adanya keluhan dari keluarga yang nantinya akan menurunkan produktivitas karyawan. Karyawan yang tidak terpenuhi keinginanya biasanya akan memiliki keinginan untuk meninggalkan perusahaan (turnover intention) dengan harapan mendapatkan kemudahan untuk menukar jam kerja dengan rekan karyawan lainnya di tempat perusahaan lain.

Berdasarkan uraian mengenai permasalahan diatas, maka dilakukan penelitian dengan tujuan untuk menganalisis pengaruh work-family conflict terhadap turnover intention dan kepuasan kerja, kemudian menganalisis pengaruh kepuasan kerja terhadap turnover intention, serta menganalisis peran mediasi kepuasan kerja pada pengaruh work-family conflict terhadap turnover intention.

Holtom dan O'neill (2004) menyatakan bahwa teori traditional turnover ini mendefinisikan dan menjelaskan bagaimana seseorang karyawan merasa kurang puas dengan posisi dalam pekerjaannya, lalu memilih untuk mencari pekerjaan baru, membandingkan posisi pekerjaan mereka saat ini dengan pekerjaan pilihannya, kemudian pergi jika mereka merasa itu merupakan alternatif yang lebih baik dari situasi saat ini yang mereka rasakan.

Irvianti dan Verina (2015) bahwa turnover merupakan wujud nyata dari turnover intention yang dapat menjadi masalah serius bagi perusahaan atau organisasi, khususnya apabila yang keluar adalah tenaga kerja yang mempunyai keahlian, kemampuan, terampil, dan berpengalaman. Tingkat turnover karyawan yang tinggi perlu mendapatkan perhatian manajemen karena tingkat turnover karyawan yang tinggi merupakan cerminan loyalitas karyawan yang rendah sehingga akan berdampak terhadap kualitas pelayanan (Evan dan Rahyuda, 2015).

Malik et al. (2015) menjelaskan work-family conflict adalah sebagai bentuk konflik di mana, tekanan peran yang terkait dengan keanggotaan dalam satu organisasi bertentangan dengan tekanan yang berasal dari keanggotaan dalam keluarga. Konflik ini terjadi jika seseorang mengalami stress dalam melakukan pekerjaannya. Studi yang dilakukan oleh Amstad et al. (2011) menunjukkan bahwa work family conflict bersumber pada hal-hal yang terjadi dalam lingkungan pekerjaan (work-related outcomes), seperti kepuasan kerja, komitmen organisasi dan performa kerja.

Menurut Kusuma dkk. (2018) kepuasan kerja merupakan sikap positif karyawan terhadap pekerjaan dan segala sesuatu yang dihadapi di lingkungan kerja. Singh dan Nayak (2015) menyatakan bahwa kepuasan kerja dapat diukur melalui situasi pekerjaan dan sikap karyawan terhadap suatu pekerjaannya. Seorang 
karyawan yang dapat dikatakan puas dalam bekerja, bahwa tingkat kepuasan yang dirasakan karyawan tinggi terkait dengan pekerjaan mereka (Puangyoykeaw dan Nishide, 2015).

Berdasarkan telaah dan kajian penelitian terdahulu, maka dapat disusun hipotesis sebagai berikut:

$\mathrm{H}_{1}$ : work-family conflict berpengaruh positif signifikan terhadap turnover intention.

$\mathrm{H}_{2}$ : work-family conflict berpengaruh negatif signifikan terhadap kepuasan kerja.

$\mathrm{H}_{3}$ : kepuasan kerja berpengaruh negatif signifikan terhadap turnover intention.

$\mathrm{H}_{4}$ : peran kepuasan kerja memediasi pengaruh work-family conflict terhadap turnover intention.

Berdasarkan kajian penelitian terdahulu dan hipotesis yang sudah dirumuskan, maka model konseptual dalam penelitian ini adalah sebagai berikut:

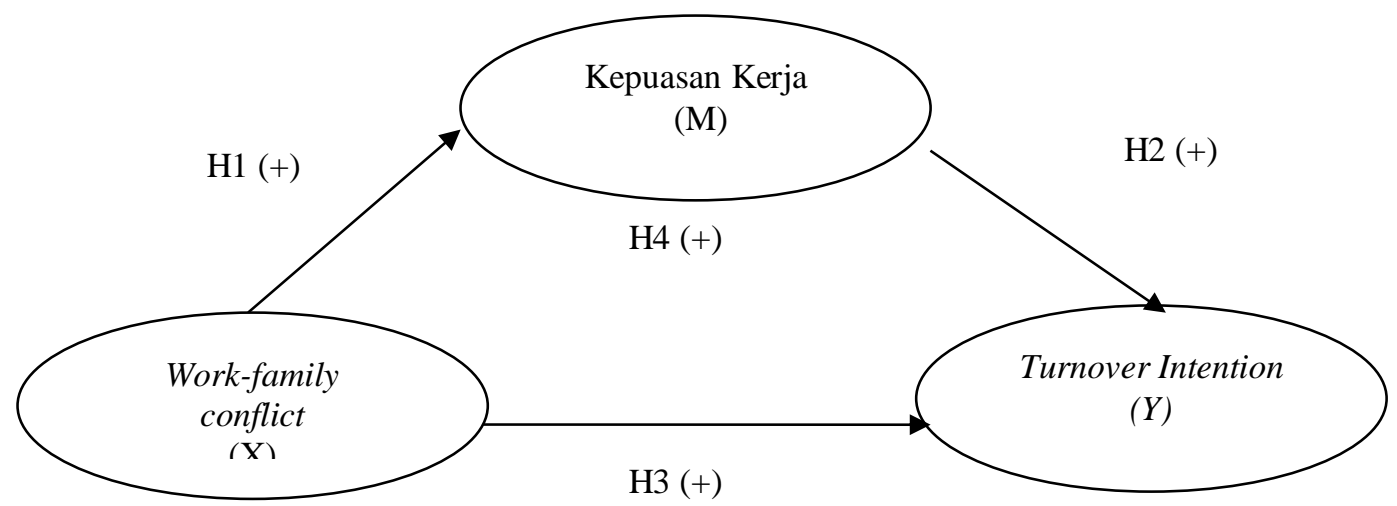

\section{Gambar 1. Model Konseptual}

Sumber : kajian penelitian terdahulu

\section{METODE PENELITIAN}

Penelitian ini menggunakan pendekatan kuantitatif yang berbentuk asosiatif kausalitas (sebab dan akibat) yaitu penelitian bertujuan untuk mengetahui pengaruh dua variabel atau lebih yaitu menjelaskan tentang peran mediasi kepuasan kerja pada pengaruh work-family conflict terhadap turnover intention. Variabel-variabel dalam penelitian ini terdiri dari variabel eksogen, variabel endogen dan variable mediasi. Variabel-variabel yang diteliti diantaranya turnover intention (Y), workfamily conflict (X) dan kepuasan kerja (M).

Penelitian ini dilakukan di Hotel Dafam Savvoya Seminyak, Badung, Bali, Indonesia yang berlokasi di Jalan Mertanadi No. 14, Seminyak, Badung, Bali, Indonesia. Pemilihan lokasi penelitian ini didasarkan karena adanya fenomena turnover karyawan Hotel Dafam Savvoya Seminyak, Badung, Bali, Indonesia. Hal ini dapat dijadikan bahwa terdapat permasalahan mengenai turnover intention.

Variabel yang diteliti dalam penelitian ini terdapat 3 jenis variabel diantaranya variabel eksogen, variabel endogen dan variabel mediasi yang masingmasing diukur menggunakan indikator sebagai berikut: 
Tabel 2.

Rangkuman Variabel dan Indikator Penelitian

\begin{tabular}{|c|c|c|c|}
\hline No & Variabel & Indikator & Sumber \\
\hline 1. & $\begin{array}{l}\text { Turnover } \\
\text { Intention } \\
\text { (Variabel } \\
\text { endogen) }\end{array}$ & $\begin{array}{l}\text { 1. Pikiran untuk keluar } \\
\text { 2. Keinginan untuk mencari pekerjaan lain } \\
\text { 3. Keinginan untuk meninggalkan organisasi dalam beberapa } \\
\text { bulan kedepan }\end{array}$ & $\begin{array}{l}\text { Jehanzeb } \\
\text { et al. } \\
(2013)\end{array}$ \\
\hline 2. & $\begin{array}{l}\text { Work- } \\
\text { family } \\
\text { conflict } \\
\text { (Variabel } \\
\text { Eksogen) }\end{array}$ & $\begin{array}{l}\text { 1. Time-based conflict } \\
\text { (1) Kurangnya ketersediaan waktu bersama keluarga } \\
\text { (2) Gangguan keluarga sehingga mengganggu } \\
\text { produktivitas pekerjaan } \\
\text { 2. Strain-based conflict } \\
\text { (1) Beban kerja yang melebihi kapasitas tanggung } \\
\text { jawab } \\
\text { (2) Tekanan dari peran kerja } \\
\text { 3. Behavior-based conflict } \\
\text { (1) Keluhan keluarga yang mengganggu pekerjaan } \\
\text { (2) Kurangnya waktu istirahat dalam bekerja }\end{array}$ & $\begin{array}{l}\text { Jendra } \\
\text { dan } \\
\text { Riana } \\
(2015)\end{array}$ \\
\hline 3. & $\begin{array}{l}\text { Kepuasan } \\
\text { Kerja } \\
\text { (Variabel } \\
\text { Mediasi) }\end{array}$ & $\begin{array}{l}\text { 1. Pekerjaan itu sendiri } \\
\text { 2. Gaji } \\
\text { 3. Kesempatan promosi } \\
\text { 4. Pengawasan } \\
\text { 5. Rekan Kerja }\end{array}$ & $\begin{array}{l}\text { Robbins } \\
\text { dan } \\
\text { Judge } \\
(2015: 50)\end{array}$ \\
\hline
\end{tabular}

Sumber: Kajian penelitian sebelumnya, 2020

Populasi dalam penelitian ini adalah karyawan Hotel Dafam Savvoya Seminyak, Badung, Bali, Indonesia yang berjumlah sebanyak 50 orang. Sampel yang digunakan dalam penelitian ini menggunakan teknik purposive sampling yaitu teknik penentuan sampel dengan pertimbangan tertentu seperti penentuan sampel dengan jabatan, status berkeluarga dan tidak berkeluarga. Sampel yang digunakan dalam penelitian ini sebanyak 33 orang yang berstatus menikah dan tidak menerlibatkan General Manager.

Akan tetapi tuntutan tersebut tidaklah membuat General Manager berkeinginan untuk meninggalkan perusahaan dan 16 orang karyawan tidak diikutsertakan sebagai sampel dikarenakan karyawan tersebut belum berkeluarga sehingga work-family conflict tidak bisa dirakasan oleh ke-16 karyawan tersebut. Namun tidak memungkiri ke-16 karyawan juga dapat merasakan work-family conflict sesuai dengan indikator kurangnya ketersediaan waktu bersama keluarga, kurangnya waktu istirahat dalam bekerja serta karyawan yang tidak berstatus menikah juga merasakan konflik pekerjaan keluarga seperti seringnya berlembur untuk menyelesaikan pekerjaan yang membuat karyawan sangat kurang untuk beristirahat dan kurangnya waktu berkumpul bersama keluarga. Selanjutnya data dalam penelitian ini dikumpulkan menggunakan kuesioner dan dianalisis menggunakan Analisis statistik deskriptif dan analisis jalur (path analysis). Namun sebelum dilakukan analisis jalur, data diuji menggunakan uji instrumen penelitian dan uji asumsi klasik. Kemudian untuk pengujian pengaruh tidak langsung atau mediasi dilakukan dengan uji sobel. 


\section{HASIL DAN PEMBAHASAN}

Penelitian ini menggunakan 33 orang karyawan pada Hotel Dafam Savvoya Seminyak, Badung, Bali, Indonesia sebagai responden sesuai dengan ukuran sampel yang digunakan. Penggambaran mengenai responden dalam penelitian ini akan dijelaskan dengan menyajikan karakteristik responden yang didasarkan pada tiga aspek yaitu umur, jenis kelamin dan pendidikan terakhir dengan hasil seperti yang tercantum pada Tabel 3. berikut.

Tabel 3.

Karakteristik Responden Hotel Dafam Savvoya Seminyak

\begin{tabular}{cccc}
\hline No. & Usia & $\begin{array}{c}\text { Jumlah Responden } \\
\text { (Orang) }\end{array}$ & $\begin{array}{c}\text { Persentase } \\
\text { Responden }(\%)\end{array}$ \\
\hline 1 & $20-30$ Tahun & 15 & 45,46 \\
2 & $31-40$ Tahun & 18 & 54,54 \\
& Jumlah & $\mathbf{3 3}$ & $\mathbf{1 0 0}$ \\
No. & Jenis Kelamin & Jumlah Responden & Persentase \\
(Orang) & Responden $(\%)$ \\
1 & Laki-Laki & 21 & 63,64 \\
2 & Perempuan & 12 & 36,36 \\
& Jumlah & $\mathbf{3 3}$ & $\mathbf{1 0 0}$ \\
No. & Pendidikan Terakhir & Jumlah Responden & Persentase \\
1 & SMA/SMK & $($ Orang) & Responden $(\%)$ \\
2 & Diploma & 8 & 24,24 \\
3 & Sarjana & 20 & 60,60 \\
& Jumlah & 5 & 15,16 \\
No. & Status Perkawinan & $\mathbf{3 3}$ & $\mathbf{1 0 0}$ \\
1 & Menikah & $($ Orang) & Persentase \\
& Jumlah & 33 & Responden $(\%)$ \\
\hline
\end{tabular}

Sumber: Data primer diolah, 2020

Tabel 3. menunjukkan terdapat tiga karakteristik responden yaitu usia, jenis kelamin, pendidikan terakhir dan status perkawinan. Sebagian besar responden dalam penelitian ini berusia 31 sampai 40 tahun dengan persentase sebesar 54,54 persen atau sebanyak 18 orang yang merupakan kelompok dalam usia produktif yang berarti sudah memiliki pengalaman yang cukup dalam bekerja sehingga mampu bekerja dengan baik. Penelitian ini didominasi dengan responden berjenis kelamin laki-laki dengan keseluruhan persentase sebesar 63,64 persen atau 21 orang karena perusahaan ini para pekerjanya sebagian besar merupakan food \& beverage, engineering dan houskeeping, sisanya sebesar 36,36 persen atau 12 orang berjenis kelamin perempuan. Pendidikan terakhir responden sebagian besar merupakan lulusan Diploma dengan persentase sebesar 60,60 persen atau 20 orang, seseorang yang sudah menempuh pendidikan hingga jenjang Diploma diasumsikan memiliki pemahaman dan kemampuan yang cukup baik dalam menyelesaikan pekerjaan. Status perkawinan penelitian ini didominasi dengan responden yang sudah menikah dengan persentase 100 persen dikarenakan sebagian besar sudah menikah atau 
sudah memiliki keluarga karena sampel yang digunakan dalam penelitian ini yang sudah berstatus menikah Tabel 4.

Hasil rekapitulasi uji validitas dan reliabilitas penelitian ini terdapat pada

Tabel 4.

Hasil Uji Validitas dan Reliabilitas

\begin{tabular}{|c|c|c|c|c|c|}
\hline Variabel & Indikator & $\begin{array}{c}\text { Koefisien } \\
\text { Korelasi } \\
\end{array}$ & $\begin{array}{c}\text { Sig. } \\
\text { (2tailed) }\end{array}$ & $\begin{array}{c}\text { Cronbach's } \\
\text { Alpha }\end{array}$ & Keterangan \\
\hline \multirow{5}{*}{$\begin{array}{l}\text { Work-family } \\
\text { conflict }(\mathrm{X})\end{array}$} & $\mathrm{X}_{1}$ & 0,875 & 0,000 & 0,943 & Valid dan \\
\hline & $\mathrm{X}_{2}$ & 0,881 & 0,000 & & Reliabel \\
\hline & $\mathrm{X}_{3}$ & 0,863 & 0,000 & & \\
\hline & $\mathrm{X}_{4}$ & 0,903 & 0,000 & & \\
\hline & $\mathrm{X}_{5}$ & 0,906 & 0,000 & & \\
\hline \multirow{6}{*}{$\begin{array}{l}\text { Kepuasan kerja } \\
\text { (M) }\end{array}$} & $\mathrm{X}_{6}$ & 0,895 & 0,000 & & \\
\hline & $\mathrm{M}_{1}$ & 0,854 & 0,000 & 0,885 & Valid dan \\
\hline & $\mathrm{M}_{2}$ & 0,784 & 0,000 & & Reliabel \\
\hline & $\mathrm{M}_{3}$ & 0,885 & 0,000 & & \\
\hline & $\mathrm{M}_{4}$ & 0,744 & 0,000 & & \\
\hline & $\mathrm{M}_{5}$ & 0,868 & 0,000 & & \\
\hline \multirow{3}{*}{$\begin{array}{c}\text { Turnover } \\
\text { intention (Y) }\end{array}$} & $\mathrm{Y}_{1}$ & 0,951 & 0,000 & 0,920 & Valid dan \\
\hline & $\mathrm{Y}_{2}$ & 0,898 & 0,000 & & Reliabel \\
\hline & $\mathrm{Y}_{3}$ & 0,935 & 0,000 & & \\
\hline
\end{tabular}

Sumber: Data primer diolah, 2020

Hasil uji validitas pada Tabel 4. diatas menunjukkan bahwa seluruh variabel memiliki nilai koefisien korelasi dengan skor total seluruh item pernyataan lebih besar dari 0,30. Hal ini menunjukkan bahwa butir-butir pernyataan dalam instrument penelitian tersebut valid. Hasil juga menunjukkan bahwa seluruh instrumen penelitian memiliki koefisien Cronbach's Alpha lebih dari 0,60. Hal ini dapat dikatakan bahwa semua instrumen reliabel sehingga dapat digunakan untuk melakukan penelitian

Skor pada penelitian ini memiliki nilai tertinggi maksimal 5 dan terendah minimal 1, sehingga dapat disusun kriteria pengukuran sebagai berikut:

$$
\begin{array}{ll}
1,00-1,80 & \text { : Sangat Rendah } \\
1,80-2,60 & \text { : Rendah } \\
2,60-3,40 & \text { : Cukup Tinggi } \\
3,40-4,20 & \text { : Tinggi } \\
4,20-5,00 & \text { : Sangat Tinggi }
\end{array}
$$

Deskripsi data kuesioner yang terdiri atas pernyataan responden berdasarkan masing-masing variabel, yaitu turnover intention, work-family conflict, dan kepuasan kerja akan dijelaskan pada Tabel 5.

Berdasarkan jawaban responden pada variabel turnover intention pada Tabel 5. secara keseluruhan memiliki rata-rata sebesar 3,52 yang berarti niat karyawan untuk meninggalkan perusahaan (turnover intention) tinggi. Rata-rata jawaban responden tertinggi pada pernyataan Y1 "Saya sering berpikir untuk meninggalkan organisasi ini" dengan nilai skor rata-rata 3,58. Hal ini mengindikasikan bahwa karyawan sering berfikir untuk meninggalkan organisasi dikarenakan sulitnya 
karyawan menukar jam kerja apabila ada kepentingan dikeluarga ataupun diluar lingkungan hotel. Nilai responden terendah pada pernyataan Y3 "Saya memiliki niat untuk keluar dari organisasi dalam beberapa bulan ke depan" dengan skor rata-rata 3,42. Hal ini mengungkapkan bahwa karyawan memiliki niat untuk keluar dari organisasi dalam beberapa bulan ke depan.

Tabel 5.

Deskripsi Variabel Turnover Intention (Y)

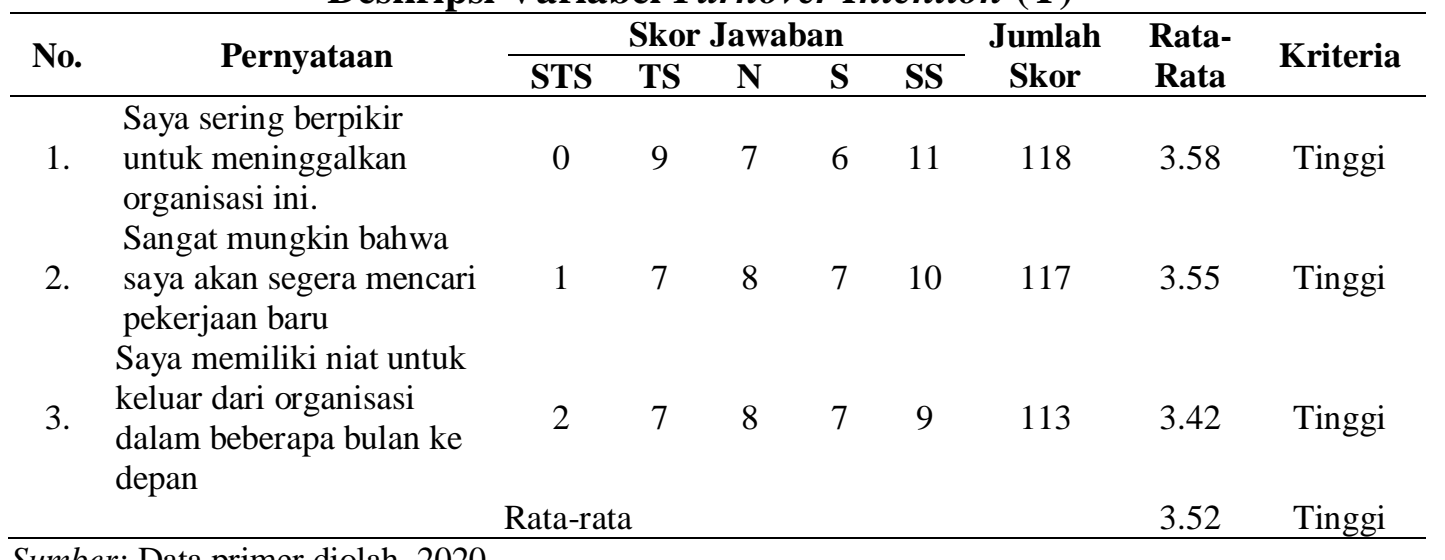

Sumber: Data primer diolah, 2020

Variabel Work-Family Conflict merupakan variabel terikat pada penelitian ini, yang diukur menggunakan 6 indikator dan ditanggapi melalui 5 poin skala likert. Hasil penelitian responden terhadap variabel Work-Family Conflict dapat dilihat lebih rinci pada Tabel 6. berikut.

Berdasarkan jawaban responden pada variabel work-family conflict pada Tabel 6. secara keseluruhan memiliki rata-rata sebesar 3,37 yang berarti karyawan memiliki peran ganda yang akan menimbulkan konsekuensi yang negatif yang tergolong dalam kriteria tinggi.

Rata-rata jawaban responden tertinggi pada pernyataan X5 "Keluhan pada keluarga mengganggu saya dalam bekerja" dengan nilai skor rata-rata 3,45. Kondisi ini menyatakan bahwa karyawan merasa terganggu oleh keluhan dari keluarga. Nilai skor yang paling rendah ditunjukkan pada pernyataan X6 "Saya tidak memiliki waktu yang cukup untuk beristirahat" dengan nilai skor 3,27. Hal ini membuktikan bahwa karyawan sering mengungkapkan kurangnya waktu yang cukup untuk beristirahat.

Berdasarkan jawaban responden pada variabel kepuasan kerja pada Tabel 7. secara keseluruhan memiliki rata-rata sebesar 3,48 yang berarti sikap positif karyawan terhadap pekerjaan dan segala sesuatu yang dihadapi di lingkungan kerja yang tergolong dalam kriteria tinggi.

Rata-rata jawaban reponden tertinggi pada pernyataan M4 "Saya merasa puas karena adanya dukungan yang diberikan kepada karyawan" dan pernyataan M5 "Saya merasa puas karena adanya kerjasama yang baik dengan rekan kerja" dengan nilai skor rata-rata 3,58. Situasi ini mengindikasikan bahwa pernyataan diatas karyawan setuju dan merasa puas karena adanya dukungan dari organisasi dan kerja sama dari rekan kerja yang terjalin dengan baik. Jawaban dengan nilai skor paling rendah pada pertanyaan M1 "Saya merasa puas karena dapat menguasai pekerjaan 
yang diberikan." dengan rata-rata 3,21. Peristiwa ini menunjukkan bahwa karyawan merasa tidak puas dengan pekerjaan yang diberikan dikarenakan karyawan tersebut belum menguasinya.

Pengujian data dalam penelitian ini menggunakan teknik analisis jalur (Path Analysis), dimana analisis jalur adalah perluasan dari analisis regresi linear berganda untuk menguji hubungan kausalitas antara 2 atau lebih variabel. Perhitungan koefisien path dilakukan dengan analisis regresi melalui software SPSS 18.0 for Windows, diperoleh hasil yang ditunjukan pada Tabel 8. berikut.

Tabel 6.

Deskripsi Variabel Work-Family Conflict (X)

\begin{tabular}{|c|c|c|c|c|c|c|c|c|c|}
\hline \multirow{2}{*}{ No. } & \multirow{2}{*}{ Pernyataan } & \multicolumn{5}{|c|}{ Skor Jawaban } & \multirow{2}{*}{$\begin{array}{c}\text { Jumlah } \\
\text { Skor }\end{array}$} & \multirow{2}{*}{$\begin{array}{l}\text { Rata- } \\
\text { Rata }\end{array}$} & \multirow{2}{*}{ Kriteria } \\
\hline & & STS & TS & $\mathbf{N}$ & $\mathbf{S}$ & SS & & & \\
\hline 1. & $\begin{array}{l}\text { Kurangnya ketersediaan } \\
\text { waktu bersama keluarga } \\
\text { oleh karena pekerjaan }\end{array}$ & 2 & 4 & 12 & 11 & 4 & 110 & 3.33 & Netral \\
\hline 2. & $\begin{array}{l}\text { Permasalahan keluarga } \\
\text { mengganggu } \\
\text { produktivitas saya dalam } \\
\text { bekerja }\end{array}$ & 0 & 10 & 6 & 12 & 5 & 111 & 3.36 & Netral \\
\hline 3. & $\begin{array}{l}\text { Beban kerja saya } \\
\text { melebihi kapasitas } \\
\text { tanggung jawab saya } \\
\text { pada perusahaan }\end{array}$ & 1 & 8 & 8 & 9 & 7 & 112 & 3.39 & Netral \\
\hline 4. & $\begin{array}{l}\text { Saya merasa tertekan } \\
\text { oleh perasaan saya dalam } \\
\text { pekerjaan }\end{array}$ & 4 & 6 & 6 & 7 & 10 & 112 & 3.39 & Netral \\
\hline 5. & $\begin{array}{l}\text { Keluhan pada keluarga } \\
\text { mengganggu saya dalam } \\
\text { bekerja }\end{array}$ & 2 & 7 & 9 & 4 & 11 & 114 & 3.45 & Tinggi \\
\hline 6. & $\begin{array}{l}\text { Saya tidak memiliki } \\
\text { waktu yang cukup untuk } \\
\text { beristirahat }\end{array}$ & 4 & 5 & 8 & 10 & 6 & 108 & 3.27 & Netral \\
\hline \multicolumn{8}{|c|}{ Rata-rata } & 3.37 & Tinggi \\
\hline
\end{tabular}

Sumber: Data primer diolah, 2020

Berdasarkan hasil analisis jalur substruktur 1 seperti yang disajikan pada Tabel 8. maka dapat dibuat persamaan struktural sebagai berikut :

$\mathrm{M}=-0,567 \mathrm{X}+\mathrm{e}_{1}$

Nilai koefisien regresi variabel work-family conflict bernilai positif dengan nilai signifikansi uji t kurang dari 0,05. Hal ini menunjukkan bahwa variabel workfamily conflict memiliki pengaruh positif yang signifikan terhadap variabel Kepuasan kerja. Besarnya pengaruh variabel bebas terhadap variabel terikat yang ditunjukkan oleh nilai determinasi total (R Square) sebesar 0,692 mempunyai arti bahwa sebesar 69,2 persen variasi Kepuasan kerja dipengaruhi oleh variasi workfamily conflict, sedangkan sisanya sebesar 30,8 persen dijelaskan oleh faktor lain yang tidak dimasukkan ke dalam model. 
Tabel 7.

Deskripsi Variabel Kepuasan Kerja (M)

\begin{tabular}{|c|c|c|c|c|c|c|c|c|c|}
\hline \multirow{2}{*}{ No } & \multirow{2}{*}{ Pernyataan } & \multicolumn{5}{|c|}{ Skor Jawaban } & \multirow{2}{*}{$\begin{array}{c}\text { Jumlah } \\
\text { Skor }\end{array}$} & \multirow{2}{*}{$\begin{array}{l}\text { Rata- } \\
\text { Rata }\end{array}$} & \multirow{2}{*}{ Kriteria } \\
\hline & & STS & TS & $\mathbf{N}$ & $\mathbf{S}$ & SS & & & \\
\hline 1. & $\begin{array}{l}\text { Saya merasa puas karena dapat } \\
\text { menguasai pekerjaan yang } \\
\text { diberikan. }\end{array}$ & 2 & 8 & 9 & 9 & 5 & 106 & 3.21 & Netral \\
\hline 2. & $\begin{array}{l}\text { Saya merasa puas karena } \\
\text { pemberian gaji dan tunjangan } \\
\text { yang sesuai dengan beban kerja }\end{array}$ & 0 & 4 & 13 & 11 & 5 & 116 & 3.52 & Tinggi \\
\hline 3. & $\begin{array}{l}\text { Saya merasa puas karena adanya } \\
\text { kesesuaian pelaksanaan promosi } \\
\text { jabatan dengan standar yang } \\
\text { telah ditetapkan }\end{array}$ & 2 & 4 & 9 & 10 & 8 & 117 & 3.55 & Tinggi \\
\hline 4. & $\begin{array}{l}\text { Saya merasa puas karena adanya } \\
\text { dukungan yang diberikan kepada } \\
\text { karyawan }\end{array}$ & 1 & 3 & 10 & 14 & 5 & 118 & 3.58 & Tinggi \\
\hline 5. & $\begin{array}{l}\text { Saya merasa puas karena adanya } \\
\text { kerjasama yang baik dengan } \\
\text { rekan kerja }\end{array}$ & 2 & 3 & 10 & 10 & 8 & 118 & 3.58 & Tinggi \\
\hline \multicolumn{8}{|c|}{ Rata-rata } & 3.48 & Tinggi \\
\hline
\end{tabular}

Tabel 8.

Hasil Analisis Jalur 1

\begin{tabular}{|c|c|c|c|c|c|}
\hline \multirow{2}{*}{ Variabel } & \multicolumn{2}{|c|}{ Unstandardized Coefficients } & \multirow{2}{*}{$\begin{array}{c}\begin{array}{c}\text { Standardized } \\
\text { Coefficients }\end{array} \\
\text { Beta } \\
\end{array}$} & \multirow[b]{2}{*}{$\mathbf{T}$} & \multirow[b]{2}{*}{ Sig. } \\
\hline & B & Std. Error & & & \\
\hline (Constant) & 28,874 & 1,438 & & 20,075 & 0,000 \\
\hline Work-family conflict & $-0,567$ & 0,068 & $-0,832$ & $-8,347$ & 0,000 \\
\hline Dependen variabel & \multicolumn{2}{|c|}{ Kepuasan kerja } & & & \\
\hline R Square & \multicolumn{2}{|c|}{0,692} & & & \\
\hline Adjusted R Square & \multicolumn{2}{|c|}{0,682} & & & \\
\hline F Statistik & \multirow{2}{*}{\multicolumn{2}{|c|}{$\begin{array}{c}69,680 \\
0,000\end{array}$}} & & & \\
\hline Signifikansi Uji F & & & & & \\
\hline
\end{tabular}

Selanjutnya hasil uji analisis jalur kedua dalam penelitian ini dapat dilihat pada Tabel 9.

Berdasarkan hasil analisis jalur substruktur 2 seperti yang disajikan pada Tabel 9, maka dapat dibuat persamaan struktural sebagai berikut :

$$
\mathrm{Y}=0,347 \mathrm{X}-0,258 \mathrm{M}+\mathrm{e}_{2}
$$

Nilai signifikansi masing-masing variabel bebas kurang dari 0,050. Hal ini menunjukkan bahwa semua variabel bebas memiliki pengaruh yang signifikan terhadap variabel terikat. Besarnya pengaruh variabel bebas terhadap variabel terikat yang ditunjukkan oleh nilai determinasi total ( $\mathrm{R}$ Square) sebesar 0,889 mempunyai arti bahwa sebesar 88,9 persen variasi Turnover intention dipengaruhi oleh variasi work-family conflict dan kepuasan kerja, sedangkan sisanya sebesar 11,1 persen dijelaskan oleh faktor lain yang tidak dimasukkan ke dalam model. 
Tabel 9.

Hasil Analisis Jalur 2

\begin{tabular}{|c|c|c|c|c|c|}
\hline \multirow[t]{2}{*}{ Variabel } & \multicolumn{2}{|c|}{$\begin{array}{l}\text { Unstandardized } \\
\text { Coefficients }\end{array}$} & \multirow{2}{*}{$\begin{array}{c}\begin{array}{c}\text { Standardized } \\
\text { Coefficients }\end{array} \\
\text { Beta }\end{array}$} & \multirow[b]{2}{*}{$\mathbf{T}$} & \multirow[b]{2}{*}{ Sig. } \\
\hline & B & $\begin{array}{l}\text { Std. } \\
\text { Error }\end{array}$ & & & \\
\hline (Constant) & 8,032 & 2,578 & & 3,116 & 0,004 \\
\hline Work-family conflict & 0,347 & 0,059 & 0,650 & 5,926 & 0,000 \\
\hline Kepuasan kerja & $-0,258$ & 0,086 & $-0,330$ & $\begin{array}{r}- \\
3,005\end{array}$ & 0,005 \\
\hline $\begin{array}{l}\text { Dependen variabel } \\
\text { R Square } \\
\text { Adjusted R Square } \\
\text { F Statistik } \\
\text { Signifikansi Uji F }\end{array}$ & $\begin{array}{r}\text { Turnover } \\
0,8 \\
0,8 \\
119 \\
0,0\end{array}$ & ntion & & & \\
\hline
\end{tabular}

Sumber: Data primer diolah, 2020

Berdasarkan model substruktur 1 dan substruktur 2, maka dapat disusun model diagram jalur akhir. Sebelum menyusun model diagram jalur akhir, terlebih dahulu dihitung nilai standar eror sebagai berikut :

$$
\begin{aligned}
& \mathrm{Pe}_{1}=\sqrt{1-R_{1}{ }^{2}}= \\
& =\sqrt{1-0,692}=0,555 \\
& \mathrm{Pe}_{2}=\sqrt{1-R_{2}{ }^{2}}= \\
& =\sqrt{1-0,889}=0,333
\end{aligned}
$$

Berdasarkan perhitungan pengaruh error (Pei), didapatkan hasil pengaruh error $\left(\mathrm{Pe}_{1}\right)$ sebesar 0,555 dan pengaruh error $\left(\mathrm{Pe}_{2}\right)$ sebesar 0,333. Hasil koefisien determinasi total adalah sebagai berikut :

$$
\begin{aligned}
\mathrm{R}^{2}{ }_{\mathrm{m}} & =1-\left(\mathrm{Pe}_{1}\right)^{2}\left(\mathrm{Pe}_{2}\right)^{2} \\
& =1-(0,555)^{2}(0,333)^{2} \\
& =1-(0,308)(0,111) \\
& =1-0,034=0,966
\end{aligned}
$$


Nilai determinasi total sebesar 0,966 mempunyai arti bahwa sebesar 96,6 persen variasi turnover intention pada karyawan Hotel Dafam Savvoya Seminyak, Badung, Bali, Indonesia dipengaruhi oleh variasi work-family conflict dan kepuasan kerja, sedangkan sisanya sebesar 3,4 persen djelaskan oleh faktor lain yang tidak dimasukkan ke dalam model.

Hasil koefisien jalur pada hipotesis penelitian dapat digambarkan pada Gambar 2. berikut :

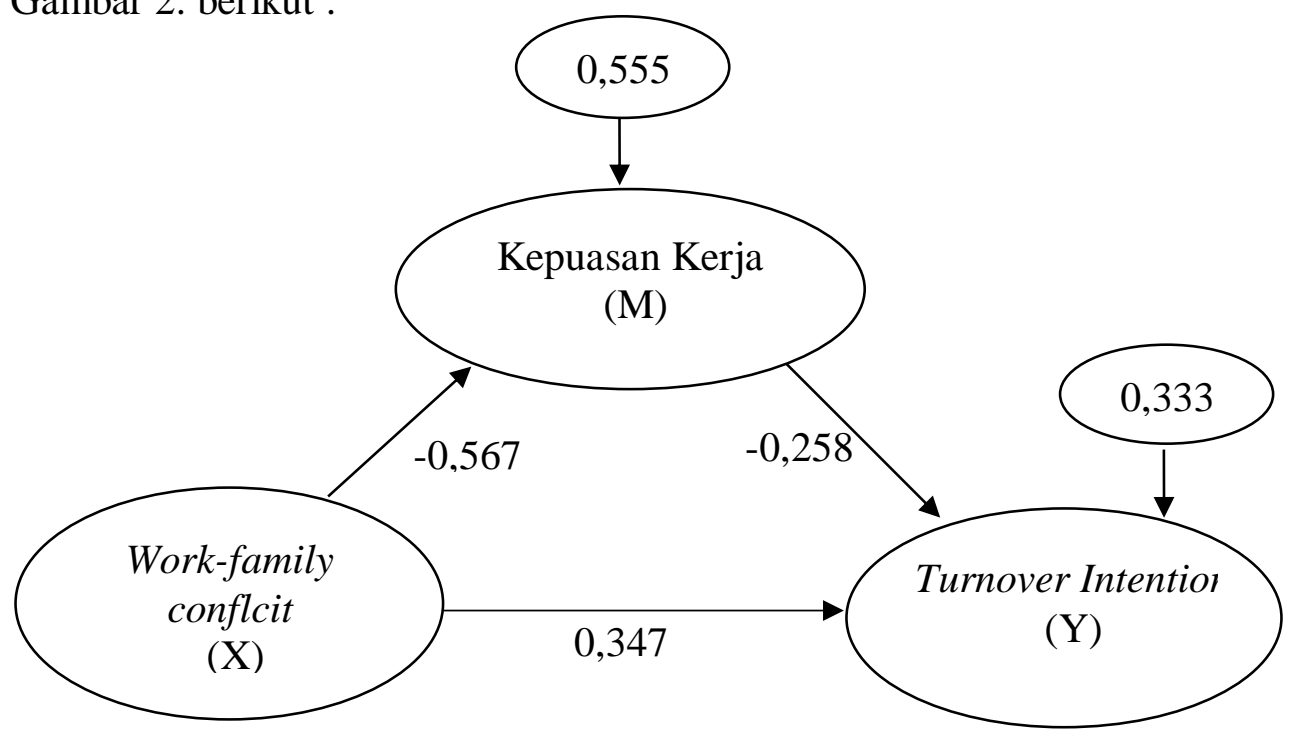

Gambar 2. Validasi Model Diagram Jalur Akhir

Sumber : Data diolah, 2020

Berdasarkan diagram jalur pada Gambar 2, maka dapat dihitung besarnya pengaruh langsung dan pengaruh tidak langsung serta pengaruh total antar variabel. Perhitungan pengaruh antar variabel dirangkum dalam Tabel 10.

Tabel 10.

Pengaruh Langsung, Tidak Langsung serta Pengaruh Total Variabel

\begin{tabular}{cccc}
\hline $\begin{array}{c}\text { Pengaruh } \\
\text { Variabel }\end{array}$ & $\begin{array}{c}\text { Pengaruh } \\
\text { Langsung }\end{array}$ & $\begin{array}{c}\text { Pengaruh Tidak Langsung Melalui } \\
\text { Kepuasan kerja } \\
(\text { Y1 })(\boldsymbol{\beta} 1 \mathbf{~ x ~} \boldsymbol{\beta 3})\end{array}$ & Pengaruh Total \\
\hline $\mathrm{X} \rightarrow \mathrm{M}$ & $-0,567$ & - & $-0,567$ \\
$\mathrm{X} \rightarrow \mathrm{Y}$ & 0,347 & 0,146 & 0,493 \\
$\mathrm{M} \rightarrow \mathrm{Y}$ & $-0,258$ & - & $-0,258$ \\
\hline
\end{tabular}

Sumber : Data primer diolah, 2020

Berdasarkan hasil perhitungan diatas menunjukkan bahwa pengaruh langsung Work-family conflict terhadap Kepuasan kerja adalah sebesar -0,567. Pengaruh langsung variabel Work-family conflict terhadap Turnover intention sebesar 0,347. Pengaruh langsung variabel Kepuasan kerja terhadap Turnover intention -0,258. Hal ini berarti bahwa variabel Turnover intention lebih besar dipengaruhi oleh Work-family conflict dibandingkan Kepuasan kerja. Sedangkan pengaruh tidak langsung variabel Work-family conflict terhadap Turnover intention melalui 
Kepuasan kerja sebesar 0,146. Jadi pengaruh total variabel Work-family conflict terhadap Turnover intention melalui Kepuasan kerja adalah sebesar 0,493.

Penelitian ini melakukan uji asumsi klasik dengan tujuan untuk memastikan hasil yang diperoleh memenuhi asumsi dasar di dalam analisis regresiUji asumsi klasik yang harus dipenuhi pada analisis regresi linear sederhana antara lain Uji Normalitas, Uji Multikolenearitas dan Uji Heterokedastisitas yang dirangkum dalam Tabel 11. berikut ini:

Tabel 11.

Rangkuman Hasil Uji Asumsi Klasik

\begin{tabular}{|c|c|c|c|c|c|}
\hline \multirow[t]{2}{*}{ Keterangan } & \multirow{2}{*}{$\begin{array}{c}\text { Hasil Uji } \\
\text { Normalitas }\end{array}$} & \multirow[t]{2}{*}{ Variabel } & \multicolumn{2}{|c|}{$\begin{array}{c}\text { Hasil Uji } \\
\text { Multikolinieritas }\end{array}$} & \multirow{2}{*}{$\begin{array}{c}\text { Hasil Uji } \\
\text { Heteroskedastisitas } \\
\text { Signifikansi } \\
\end{array}$} \\
\hline & & & Tolerance & VIF & \\
\hline$M=\beta_{1} X+e_{1}$ & 0,987 & $\begin{array}{c}\text { Work- } \\
\text { family } \\
\text { conflict }(\mathrm{X})\end{array}$ & 1,000 & 1,000 & 0,768 \\
\hline \multirow[t]{2}{*}{$Y=\beta_{2} X+\beta_{3} M+e_{2}$} & \multirow[t]{2}{*}{0,780} & $\begin{array}{l}\text { Work- } \\
\text { family } \\
\text { conflict }(\mathrm{X})\end{array}$ & 0,308 & 3,248 & 0,507 \\
\hline & & $\begin{array}{l}\text { Kepuasan } \\
\text { kerja (M) }\end{array}$ & 0,308 & 3,248 & 0,311 \\
\hline
\end{tabular}

Sumber: Data diolah, 2020

Seluruh uji asumsi klasik dalam Tabel 11. sudah memenuhi syarat uji karena memperoleh nilai signifikansi uji normalitas dan uji heterosekdastisitas yang lebih dari 0,05 , kemudian memiliki nilai tolerance kurang dari $10 \%$ dan VIF yang lebih dari 10, maka model analisis jalur (path analysis) layak dilakukan lebih lanjut.

Pengujian pengaruh tidak langsung variabel Work-family conflict (X) terhadap variabel Turnover intention (Y) melalui variabel Kepuasan kerja (M) diukur menggunakan rumus sebagai berikut :

$$
\begin{aligned}
& S_{b 1 b 3}=\sqrt{(0,258)^{2}(0,068)^{2}+(0,567)^{2}(0,086)^{2}+(0,068)^{2}(0,086)^{2}} \\
& S_{b 1 b 3}=0,105201
\end{aligned}
$$

Untuk menguji signifikansi pengaruh tidak langsung maka menghitung nilai $\mathrm{z}$ dari koefisien $\mathrm{ab}$ dengan rumus sebagai berikut :

$$
\begin{aligned}
& Z=\frac{b 1 b 3}{S b 1 b 3} \ldots \ldots \ldots \ldots \ldots \\
& Z=\frac{(0,567)(0,258)}{0,052151} \\
& Z=2,805
\end{aligned}
$$

Oleh karena $\mathrm{Z}$ hitung sebesar 2,805 > 1,96. Artinya Kepuasan kerja (M) merupakan variabel yang memediasi Work-family conflict (X) terhadap Turnover intention (Y) pada Karyawan Hotel Dafam Savvoya Seminyak, Badung, Bali, Indonesia atau dengan kata lain Work-family conflict berpengaruh secara tidak langsung terhadap Turnover intention melalui Kepuasan kerja.

Hasil penelitian menunjukkan bahwa pengaruh work-family conflict terhadap turnover intention memiliki hubungan pengaruh positif signifikan, yang dimana semakin tinggi work-family conflict dirasakan karyawan Hotel Dafam Savvoya Seminyak, Badung, Bali, Indonesia maka tingkat turnover intention semakin tinggi, sesuai dengan hasil pengujian hipotesis diperoleh nilai signifikansi 0,000 dengan 
nilai koefisien regresi positif sebesar 0,347. Nilai signifikansi $0,000<0,05$ mengindikasikan bahwa $\mathrm{H}_{1}$ diterima. Hasil ini mempunyai arti bahwa Work-family conflict berpengaruh positif dan signifikan terhadap Turnover intention karyawan Hotel Dafam Savvoya Seminyak, Badung, Bali, Indonesia. Hasil penelitian ini sesuai dengan Khan et al. (2014), Blomme et al. (2010), Nohe dan Karlheinz (2014), Ghayyur dan Jamal (2012), Utama dan Satria (2015).

Berdasarkan hasil analisis pengaruh Work-family conflict terhadap Kepuasan kerja diperoleh nilai signifikansi sebesar 0,000 dengan nilai koefisien regresi negatif sebesar -0,567. Nilai Signifikansi $0,000<0,05$ mengindikasikan bahwa $\mathrm{H}_{2}$ diterima. Hasil ini mempunyai arti bahwa work-family conflict berpengaruh negatif signifikan terhadap kepuasan kerja karyawan Hotel Dafam Savvoya Seminyak, Badung, Bali, Indonesia karena semakin tinggi tingkat work family conflict yang dirasakan maka kepuasan kerjanya akan semakin rendah. Hasil penelitian ini sesuai dengan penelitian Wulandari dan Adnyani (2016), Ariana dan Riana (2016), Hsu (2011), Laksmi dan Coolichul (2012), Nanda dan Utama (2015).

Berdasarkan hasil analisis pengaruh Kepuasan kerja terhadap Turnover intention diperoleh nilai signifikansi sebesar 0,005 dengan nilai koefisien regresi negatif sebesar -0,258. Nilai Signifikansi 0,005 < 0,05 mengindikasikan bahwa $\mathrm{H}_{3}$ diterima. Hasil ini mempunyai arti bahwa kepuasan kerja berpengaruh negatif signifikan terhadap turnover intention karyawan Hotel Dafam Savvoya Seminyak, Badung, Bali, Indonesia dikarenakan karyawan yang memiliki tingkat kepuasan kerja yang rendah maka akan meningkatkan niat untuk keluar dari perusahaan. Hasil penelitian yang dilakukan sesuai dengan penelitian Ningsih dan Putra (2019), Youcef et al. (2016), Candra dan Riana (2017), Warshawsky dan Havens (2015), Januartha dan Adnyani (2019).

Hasil uji menunjukan bahwa nilai $Z$ hitung sebesar 2,805 > 1,96 dengan nilai signifikansi $0,000<0,05$, yang dimana variabel kepuasan kerja memediasi workfamily conflict terhadap turnover intention karyawan Htoel Dafam Savvoya, Seminyak, Badung, Bali, Indonesia dengan kata lain work-family conflict berpengaruh secara tidak langsung terhadap turnover intention melalui kepuasan kerja. Hasil penelitian ini sesuai dengan penelitian Irzani dan Witjaksono (2014), Tariana dan Wibawa (2016), Paramita dan Subudi (2017), Sakawangi dan Supartha (2017), Silvyana dan Wibawa (2019).

Hasil penelitian ini mendukung teori yang digunakan sebagai dasar dalam pembuatan hipotesis bahwa work-family conflict mempengaruhi terhadap turnover intention, selain itu peran kepuasan kerja memediasi work-family conflict terhadap turnover intention. Ketika karyawan memiliki konflik-pekerjaan keluarga yang tinggi dan disertai kepuasan kerja yang dirasakan karyawan rendah maka akan meningkatkan niat untuk keluar dari perusahaan. Hal ini menunjukan bahwa hasil penelitian memperkuat teori yang digunakan yaitu traditional turnover theory.

Implikasi praktis dari penelitian ini diharapkan bagi pemimpin di Hotel Dafam Savvoya Seminyak, Badung, Bali, Indonesia dapat lebih memperhatikan work-family conflict, kepuasan kerja yang mempengaruhi turnover intention ditunjukkan dengan nilai determinasi total sebesar 0,966 mempunyai arti bahwa sebesar 96,6 persen sedangkan sisanya sebesar 3,4 persen djelaskan oleh faktor lain yang tidak dimasukkan ke dalam model ini. 


\section{SIMPULAN}

Berdasarkan hasil analisis maka dapat disimpulkan bahwa pertama Workfamily Conflict berpengaruh positif signifikan terhadap turnover intention. Kedua, Work-family Conflict berpengaruh negatif signifikan terhadap kepuasan kerja. Ketiga, Kepuasan kerja berpengaruh negatif signifikan terhadap turnover intention.. Keempat, Kepuasan kerja memediasi work-family conflict terhadap turnover intention.

Berdasarkan hasil analisis penelitian maka disarankan bagi Pihak manajemen dan departemen HRD Hotel Dafam Savvoya Seminyak untuk lebih memperhatikan turnover intention yang terjadi di perusahaan terutama pada karyawan yang ingin meninggalkan perusahaan dikarenakan sulitnya karyawan untuk menukar jam kerja bila ada kepentingan diluar perusahaan dan perusahaan harus lebih memperhatikan kenyamanan karyawannya. Pada faktor work-family conflict sebaiknya pihak manajemen dan departemen HRD Hotel Dafam Savvoya Seminyak, Badung, Bali, Indonesia memberikan toleransi kepada karyawan dalam kegiatan operasional seperti waktu yang fleksibel, jadwal kerja alternative sesuai dengan poksinya, kebijakan ijin keluarga dan agar nantinya tidak ada perselisihan didalam hubungan keluarga yang waktu tidak banyak dihabiskan di tempat kerja. Pihak manajemen juga perlu memberikan dukungan dan motivasi yang besar untuk seluruh karyawan agar tidak merasa tertekan dalam bekerja. Selain itu, Pihak manajemen dan departemen HRD Hotel Dafam Savvoya Seminyak, Badung, Bali, Indonesia sebaiknya meningkatkan pelatihan sesuai dengan standar operasional prosedur (SOP) agar karyawan mampu menguasai tugas dan tanggung jawab yang diberikan oleh pihak perusahaan supaya karyawan mampu memberikan produktivitas yang terbaik bagi perusahaan.

\section{REFERENSI}

Amstad, F. T., Meier, L. L., Fasel, U., Elfering, A., \& Semmer, N. K. (2011). A Meta-Analysis of Work-Family Conflict and Various Outcomes With a Special Emphasis on Cross-Domain Versus Matching-Domain Relations. Journal of Occupational Health Psychology, 16, 151-169.

Anwar, R. (2018). Pengaruh Kepuasan Kerja Dan Loyalitas Kerja Terhadap Organizational Citizenship Behavior (OCB) Pada Kinerja Karyawan PT. Hm. Sampoerna, Tbk Baturaja Timur Sumatera Selatan. Jurnal Manajemen Dan Bisnis Sriwijaya, 16(2), 110-121.

Ariana, I. W. J., \& Riana, I. G. (2016). Pengaruh Work-Family Conflict, Keterlibatan Kerja Dan Stres Kerja Terhadap Kepuasan Kerja Karyawan. EJurnal Manajemen Unud, 5(7), 4630-4659.

Ariansyah, R. (2019). Pengaruh Job Insecurity, Stres Kerja, Dan Kepuasan Kompensasi Terhadap Intention To Quit Karyawan PT. Mandala Finance 
TBK Cabang IDI. 5(1), 22-30.

Blomme, R. J., Rheed, A. V., \& Tromp, D. M. (2010). Work-Family Conflict asACause for Turnover Intentions in The Hospitality Industry. Tourismand Hospitality Research, 10(4), 269-285.

Candra, P. D. K., \& Riana, I. G. (2017). Peran Komitmen Organisasional Memediasi Pengaruh Kepuasan Kerja terhadap Turnover Intention. E-Jurnal Manajemen Unud, 6(10), 5287-5318.

Evan Berta, G. P., \& Rahyuda, A. G. (2015). Pengaruh Kepuasaan Kerja, Komitmen Efektif, Kotmitmen Kalkulatif dan Kotmitmen Normativeterhadap Turnover Intention Ayodya Resort Bali. E-Jurnal Ekonomi Dan Bisnis Universitas Udayana, 4(8), 2243-2268.

Fahrizal, \& Utama, I. W. M. (2017). Pengaruh Persepsi Dukungan Organisasi Terhadap Komitmen Organisasional dan Turnover Intention Karyawan Hotel Kajane MUA Ubud. E-Jurnal Manajemen Unud, 6(10), 5405-5543.

Ghayyur, M., \& Jamal, W. (2012). Work Family Conflict: A Caseofemployees Turnover Intention. Journal of Social Science Andhumanity, 1(1), 145-157.

Holtom, B. C., \& O'neill, B. S. (2004). Job Embeddedness: A Theoretical Foundation for Developing a Comprehensive Nurse Retention Plan. The Journal of Nursing Administration, 35(5), 216-227.

Hsu, Y. (2011). Work-Family Conflict and Job Satisfaction in Stressful Working Environments the Moderating Roles of Perceived Supervisor Support And Internal Locus Oof Control. International Journal Of Manpower, 32(2), 233248.

Irvianti, L. S. D., \& Verina, R. E. (2015). Analisis Pengaruh Stres Kerja, Beban Kerja, dan Lingkungan Kerja terhadap Turnover Intention Karyawan pada PT XL Axiata Tbk Jakarta. Binus Business Review, 6(1), 117-126.

Irzani, D., \& Witjaksono, A. D. (2014). Pengaruh Konflik Peran dan Ambiguitas Peran Terhadap Keinginan Keluar Karyawan dengan Kepuasan Kerja sebagai Variabel Mediasi pada PT. Asuransi Raksa Pratikarsa di Surabaya. Jurnal Ilmu Manajemen, 2(1), 266-281. Retrieved from https://drive.google.com/open?id=0B8ZDDJq_Cxu1bUx3b3NjYUZ6Uk0

Januartha, A. A., \& Adnyani, I. D. (2019). Pengaruh Job Insecurity dan Kepuasan Kerja terhadap Turnover Intention Pada Karyawan Hotel. E-Jurnal Manajemen Unud, 8(2), 7548-7575.

Jendra, A., \& Riana, I. G. (2015). Paengaruh Work-Family Conflict, Keterlibatan 
Kerja dan Stress Kerja Terhadap Kepuasan Kerja Karyawan. E-Jurnal Manajemen Unud, 5(7), 4630-4659.

Khan, M. R., Nazir, N., Kazmi, S., Khalid, A., Kiyani, T., \& Shahzad, A. (2014). Work-Family Conflict and Turnover Intentions : Mediating Effect of Stress. International Journal of Humanities and Social Science, 4(5), 92-100. Retrieved from http://www.ijhssnet.com/journals/Vol_4_No_5_1_March_2014/12removed. pdf

Ksama, I. B. P. T., \& Wibawa, I. M. A. (2016). Pengaruh Leader-MemberExchange, Role Stress dan Perceived Organizational Support Terhadap Turnover Intention. E-Jurnal Manajemen Unud, 5(10), 6174-6200. Retrieved from https://ojs.unud.ac.id/index.php/Manajemen/article/view/21245/15738

Kusuma, A. D., Sunuharjo, B. S., \& Iqbal, M. (2018). Pengaruh Lingkungan Kerja Fisik Dan Non Fisik Terhadap Kinerja Karyawan Dengan Variabel Mediator Kepuasan Kerja (Studi Pada Karyawan PT Telkomsel Branch Malang). Jurnal Administrasi Bisnis (JAB), 55(2), 68-74.

Kusuma, K. I. P., \& Mujiati, N. W. (2017). Pengaruh Perceived Organizational Support dan Komitmen Organisasional Terhadap Turnover Intention Karyawan di Hotel Alila Ubud. E-Jurnal Manajemen Unud, 6(10), 57485774.

Laksmi, N. A. P., \& Coolichul, H. (2012). Hubungan antara Konflik Peran Ganda (Work Family Conflict) dengan Kepuasan Kerja pada Karyawan bagian Produksi PT.X. Jurnal Psikologi Industri Dan Organisasi, 1(2).

Malik, S., A., A. G., \& Ain, Q., U. (2015). Role of Work Family Conflict on Organizational Commitment and Organizational Effectiveness. Arabian Journal of Business and Management Review (Nigerian Chapter), 3(1), 15126.

Nanda, N. L. N. K., \& Utama, I. W. M. (2015). Pengaruh Konflik Kerja-Keluarga Dan Kepuasan Kerja Terhadap Tingkat Turnover Intention Karyawan Pada Restoran Pizza Hut Mall Bali Galeria. E-Jurnal Manajemen Unud, 4(9), 2461-2477.

Ningsih, N. K. W. S. N., \& Putra, M. S. (2019). Pengaruh Stres Kerja, Kepuasan Kerja Dan Komitmen Organisasional Terhadap Turnover Intention. E-Jurnal Manajemen Unud, 8(10), 5907-5927.

Nohe, C., \& Karlheinz, S. (2014). Work-Family Conflict, Social Support, and Turnover Intentions: A Longitudinal Study. Journal of Vacational Behavior, $85(1), 1-12$. 
Paramita, I. G. A., \& Subudi, M. (2017). Pengaruh Konflik Pekerjaan-Keluarga Terhadap Turnover Intention Melalui Mediasi Kepuasan Kerja Pada Hoki Bank Cabang Gatot Subroto. E-Jurnal Manajemen Unud, 6(12), 6441-6470. Retrieved from https://ojs.unud.ac.id/index.php/Manajemen/article/view/33694/21492

Prayogi, H. S. (2011). The Effect of Earthworm Meal Supplementation in the Diet on Quail's Growth Performance in Attempt to Replace the Usage of Fish Meal. International Journal of Poultry Science, 10(10), 804-806.

Robbins, S. P., \& Judge, T. A. (2015). Perilaku Organisasi (Edisi Enam). Jakarta: Salemba Empat.

Sakawangi, N. D. I. S., \& Supartha, W. G. (2017). Peran Mediasi Kepuasan Kerja Pada Pengaruh Konflik Pekerjaan-Keluarga Terhadap Turnover Intention Karyawan Wanita. E-Jurnal Manajemen Unud, 6(9), 4744-4771. Retrieved from https://ojs.unud.ac.id/index.php/Manajemen/article/view/31422/20099

Sartika, D. (2014). Pengaruh Kepuasan Kerja Dan Gaya Kepemimpinan Transformasional Terhadap Keinginan Keluar Karyawan Dengan Komitmen Organisasi Sebagai Variabel Mediasi (Studi Kasus Di CV Putra Tama Jaya). Management Analysis Journal, 3(2), 25-34.

Silvyana, N. P. M., \& Wibawa, I. M. A. (2019). Peran Mediasi Kepuasan Kerja Pada Pengaruh Workfamily Conflict Terhadap Turnover Intention Kutabex Beach Front. E-Jurnal Manajemen, 8(10), 6322-6345. Retrieved from https://doi.org/10.24843/EJMUNUD.2019.v08.i10.p23

Singh, R., \& Nayak, J. K. (2015). Mediating Role of Stress Between Work-Family Conflict and Job Satisfaction Among the Police Officials Moderating Role Of Social Support. Policing: An International Journal of Police Strategies \& Management, 38(4), 738-753.

Tariana, I. W. A., \& Wibawa, I. M. A. (2016). Peran Mediasi Kepuasan Kerja Dalam Pengaruh Work Family Conflict dan Turnover Intention Pada Karyawan Wanita. E-Jurnal Manajemen Unud, 5(9), 5433-5461. Retrieved from https://ojs.unud.ac.id/index.php/Manajemen/article/view/19978/15432

Tripathi, P., \& Pandey, M. K. (2017). Examining the Relationship Between WorkFamily Conflict, Job Satisfaction and Employee's Turnover Intention. Journal of Psychosocial Research, 12(2), 451-459.

Tziner, A., Rabenu, E., Radomski, R., \& Belkin, A. (2015). Journal of Work and Organizational Psychology Work Stress and Turnover Intentions Among Hospital Physicians: the Mediating Role Of Burnout and Work Satisfaction. Journal of Work and Organizational Psychology, 31, 207-213. 
Utama, A., \& Satria. (2015). Pengaruh Work-Family Conflict Dan Kepuasan Kerja Terhadap Komitmen Organisasional Dan Turnover intention. E-Jurnal Manajemen Unud, 4(11), 3703-3737.

Warshawsky, N. E., \& Havens, D. S. (2015). Nurse Manager Job Satisfaction AndIntent To Leave. Journal Of Economics, 32(1), 32-39.

Wulandari, I. A. D., \& Adnyani, I. G. A. D. (2016). Pengaruh Work Family Coflict terhadap Turnover Intention Melalui Mediasi Kepuasan Kerja pada Hotel Grand Inna Kuta. 5(10).

Youcef, S., Ahmed, S. S., \& Ahmed, B. (2016). The Impact of Job Satisfaction by the Existence of Organizational Commitment, and of Organizational Commitment, and Inten to Stay as Intermediates Variables Using approach PLS In Sample Worker Department of Transport Saida. 6(6), 198-202. 